\title{
Fale com eles! O trabalho interpretativo e a produção de consenso na pesquisa qualitativa em saúde: inovaçôes a partir de desenhos participativos
}

\section{| ${ }^{1}$ Rosana Onocko Campos I}

Resumo: O objetivo deste artigo é discutir uma forma de se trabalhar com pesquisa qualitativa interpretativa, a partir de técnicas participativas, incluindo validação e produção de consenso, e a construção de narrativas. As narrativas, construídas pelos pesquisadores, seguindo os núcleos argumentais, tornam o material denso, mantendose fiel à história. Em um segundo momento, esta narrativa é apresentada aos sujeitos entrevistados (momento hermenêutico), com a função de validar os dados e produzir efeitos de intervenção. Estes efeitos de narratividade são evidenciados no aprofundamento das questōes ou temas pouco desenvolvidos na primeira discussão. No processo de interpretação, não se buscam significados por trás do texto, senão que se procura colocar o mundo (nossas questôes) na frente dele, não negando com isso a existência do latente, mas optando-se pelo manifesto em virtude do posicionamento ético-político da própria pesquisa (implicação e olhar avaliativo dos sujeitos da pesquisa). Por fim, a construção de consenso é revista para se adequar aos princípios da inclusão e da diversidade, e se chega a ele via espaço de heterogeneidade de participantes, que chamamos de oficina de construção de consenso, com discussão, revisão de posicionamentos, encontros e discordâncias. Aponta-se o valor de mediação do testemunho de pacientes e familiares como uma forma especial de empoderamento.

> Palavras-chave: pesquisa qualitativa, pesquisa participativa baseada na comunidade, metodologia, narrativa, pesquisa avaliativa.
1 Médica, especialista em Clínica Médica; mestre e doutora em Saúde Coletiva. Departamento de Saúde Coletiva, Faculdade de Ciências Médicas da Unicamp. Endereço eletrônico: rosanaoc@mpc.com.br 
Em geral, há concordância entre os pesquisadores que usam métodos qualitativos de que a pesquisa qualitativa seria útil para responder as perguntas sobre o "como?" e o "por quê?". Os objetos dessas pesquisas seriam sempre históricos, sui generis, sujeitos a interpretação e estudados em seu ambiente natural (e não em um laboratório). A história dos estudos qualitativos permitiu chegar a um novo patamar em que se busca, hoje, superar o dualismo epistemológico em que a abordagem explicativa/compreensiva é colocada em oposição ao monismo positivista (uma suposta única e verdadeira boa forma para conhecer a realidade). Procura-se a complementaridade entre ambas as abordagens, sempre que conveniente. Poderíamos afirmar que para testar como funciona um antibiótico é melhor utilizar o método quantitativo, mas, por exemplo, para saber como se sente uma pessoa obrigada a tomar uma medicação todos os dias, é melhor uma abordagem qualitativa, e para avaliar serviços de saúde muitas vezes podem-se utilizar combinações de ambas.

O paradigma predominante na ciência contemporânea parece desconhecer a atual conjuntura de mudança social acelerada e a intensa diversificação das esferas da vida que não podem ser estudadas pela via dedutiva clássica (teste empírico de teorias prévias). Paradoxalmente, nunca antes houve tal associação de saber-poder, o discurso científico assumindo o caráter de verdade indiscutível e óbvia... Evidente!

Desde Dilthey, se aceita que uma das modalidades de estudo das ciências humanas e sociais é a interpretação compreensiva. Nessa abordagem, tornar transparente o processo de investigação seria requisito de sua qualidade (por isso a parte descritiva da metodologia requer uma escrita mais detalhada que nos estudos quantitativos). A análise é realizada em profundidade, e para isso precisamos de material descrito de maneira densa, meticulosamente detalhado. Nosso material de campo não se coleta (não está dado, senão que é produzido na relação) por isso nossos estudos não são repetíveis, mas devemos dar pistas ao leitor sobre as condições que fizeram possível essa produção de material e não outra.

A questão da validade das pesquisas qualitativas tem sido bastante discutida em tempos recentes (FLICK, 2004; FOSSEY et al., 2002; MORSE, 2006). Alguns autores sustentam que essa validade pode ser procurada por meio de: 
- utilização de múltiplas técnicas de "coleta" de material;

- vários pesquisadores repetindo determinados procedimentos (como a codificação);

- repetição das técnicas de coleta de dados (repetir os grupos focais pelo menos duas vezes, por exemplo);

- reapresentação do material aos sujeitos da pesquisa para validação.

É comum utilizarmos nos estudos qualitativos amostragem intencional, mas essa terminologia, às vezes utilizada como salvo conduto e garantia da qualidade, longe de trazer uma falsa e aparentemente fácil tranquilidade aos pesquisadores, deve pressupor um meticuloso cuidado em trazer a heterogeneidade do campo de interesse para o desenho do estudo. E pressupõe também declarar explicitamente as intenções dos pesquisadores e os procedimentos de recrutamento e seleção de participantes. Generalizações são possíveis na forma teórico-conceitual, porém não do empírico, do conjunto de relações.

Uma questão pouco abordada em relação ao campo da Saúde Coletiva e das pesquisas qualitativas que desenvolvemos é a de que, geralmente, não somos Malinowski quando encaramos nossos desenhos de pesquisa. Em geral, somos índios entre os índios. Muitas vezes, compartilhamos o objeto de trabalho (as comunidades, os pacientes, as equipes) e o objetivo do trabalho (a produção de saúde) com nossos sujeitos de pesquisa. Por isso, frequentemente, precisamos mais estranhar aquilo que nos é familiar do que de processos de aculturação. Contudo, no caso de nosso grupo de pesquisa, portamos uma diferença, nossa encomenda social: somos da universidade pública, os cidadãos brasileiros nos pagam para que formemos novos profissionais e também para que produzamos conhecimento útil à sociedade. É nessa encomenda social que podemos assentar o traço que nos distingue.

Castoriadis (1987) sustentava que o dever do intelectual seria "mostrar os andaimes de seu pensamento". Consideramos esse um dever ético-político em nosso papel de pesquisadores e educadores, e radica aí a motivação para escrevermos este texto.

A caixa preta das pesquisas qualitativas é menos aberta do que seria desejável. Contudo, não deveria sê-lo, pois, em certo sentido, a transparência equivale ao nosso "p" (uma analogia com os métodos estatísticos). Devemos apresentar 
1272 detalhes de nossos procedimentos, e isso faz que seja um pouco mais árdua para nós a tarefa de escrever artigos curtos (em português ou espanhol!). Porém (e talvez por causa da restrição de espaço para os artigos nas melhores revistas), na maioria dos trabalhos, repetem-se fórmulas lacônicas, que na verdade pouco explicam ao leitor, tais como: "realizamos um estudo com análise de conteúdo" ou,"extraímos as categorias emergentes do material".

Gadamer (1997) ensinou-nos que "quando se logra compreender compreendese sempre de maneira diferente”. Por isso a compreensão é um acontecimento! Pretendemos no presente artigo apresentar e discutir uma forma de operar com pesquisa qualitativa com abordagem interpretativa, que se utiliza da construção narrativa pretendendo honrar as estratégias participativas de nossos desenhos de pesquisa.

Esperamos poder mostrar como a exploração de estratégias participativas obriga-nos a produzir algumas mudanças na forma clássica de operar as pesquisas, não por desconhecermos seus recursos técnicos consagrados, senão para dar cabida às novas questôes éticas e metodológicas decorrentes. No presente trabalho, abordaremos duas mudanças que temos experimentado em nossas pesquisas recentes: a da construção narrativa e de seus efeitos, e o das estratégias de validação e de produção de consenso participativas. Para tal, precisamos declarar qual tem sido nosso posicionamento no campo da saúde coletiva: o de uma área "aplicada". Desenvolvemos estudos na área de Política, Planejamento e Gestão no Brasil, no contexto da política pública, com grande interesse em contribuir para a melhora concreta das condições de assistência à saúde da população brasileira. Temos desenvolvido principalmente estudos avaliativos e participativos de serviços de saúde. Estudos participativos em cogestão com usuários, trabalhadores e/ou gestores. E estudos no campo da saúde mental com pessoas vulneráveis como os portadores de sofrimento psíquico grave.

Realizamos todas essas pesquisas como pesquisadores de uma universidade pública, muitas vezes trabalhando em parceria com colegas de outras universidades públicas brasileiras. Junto a um Departamento de Saúde Coletiva que possui tradição em desenvolver seus trabalhos em parceria com a rede pública local de saúde, e valendo-nos de financiamentos de agências públicas (federais: CNPq ou estaduais: Fapesp) e, recentemente, internacional (IDRC/ Canadá). 
Tendo declarado nossos objetivos e posicionamento, entraremos agora

na descrição de nosso trabalho em várias pesquisas que desenvolvemos nos últimos anos.

\section{A construção narrativa como parte do tratamento do material produzido}

O material com que trabalhamos é produzido em entrevistas ou grupos focais que são áudio-gravados. As falas são transcritas conforme técnicas habituais e consagradas. É a partir dessas transcrições que elaboramos narrativas de cada um dos grupos (ou entrevistas).

Essa construção narrativa consiste fundamentalmente em uma estratégia de tornar denso o material, mantendo-se fiel a história que nele se conta, mas não necessariamente em sua sequência temporal e tampouco reproduzindo as formas lexicais do grupo. Para tal, realizamos uma primeira operação de reconhecimento de núcleos argumentais, aos quais vamos encadeando "à maneira de uma história que se deixa seguir" (RICOEUR, 1997).

As narrativas, assim construídas, são apresentadas em um segundo encontro com os mesmos sujeitos entrevistados ou participantes do grupo focal para discussão. Repetimos os grupos com a mesma composição, com as mesmas pessoas. Chamamos esse segundo encontro de grupo (ou momento) hermenêutico e ele tem o papel de validar os dados, mas também de produzir efeitos de intervenção - à maneira de uma construção em Freud (1975[1937]).

Concebemos as narrativas como um processo de mediação entre o vivido e a possibilidade de inscrevê-lo no social, inserindo a experiência subjetiva em um campo político. Para tanto, apoiamo-nos em alguns autores que oferecem subsídios para tratar da narratividade da experiência humana sem destituíla de sua intensidade, marcada pela vivência peculiar do tempo, e por marcas identitárias (ONOCKO-CAMPOS; FURTADO, 2008).

Ricoeur (1997) diz que se uma ação pode ser narrada é porque ela já está simbolicamente mediatizada. Para o autor, as narrativas são histórias não (ainda) narradas. É a atividade narrativa que permite ao homem apreender o caráter de passagem do tempo (no sentido de algo que cessa e transita), relacionando passado, presente e futuro, e localizando-se nessa relação que 
permanece em contínuo trânsito. Portanto, a narrativa se coloca como um recurso através do qual instituímos nossa vida na temporalidade humana, podendo anunciá-la e compartilhá-la.

Trata-se na narração de objetos simbólicos, que estão na cultura e, portanto, compartilham de uma articulação com o público: por isso há sempre, então, uma inter-ação (ONOCKO-CAMPOS; FURTADO, 2008). Os agentes possuem qualidades éticas e não há ação que não suscite a provação ou a reprovação segundo uma série de valores, nos quais bondade e maldade são os pólos, pois é um traço inerente à ação o de não poder ser nunca eticamente neutra.

Hanna Arendt, na biografia que dela faz Júlia Kristeva (2002), sustenta que a vida é uma narrativa. A vida seria especificamente humana com a condição de que possa ser representada por uma narrativa e partilhada com outros homens. Somente a ação como narração e a narração como ação caracterizam essa vida "bio", especificamente humana. A atividade narrativa permite ao sujeito a restituição de sua verdade histórica, o que dá acesso a ressignificações, ou seja, a autoria da própria história. A narrativa solda, assim, as relaçôes entre vida e política, pois a vida na pólis é sempre mediada pela palavra. A memória da ação pode tornar-se ela própria ação; sendo a Pólis o lugar do inter-esse, do entre-dois.

Em nossa experiência, o trabalho narrativo contribui, por exemplo, para pesquisas acerca da experiência psicótica, na medida em que permite o compartilhamento social de tal experiência, sem destituí-la de suas singularidades. A "posterioridade da nomeação do afeto" seria um caso especial da relação referente e significante: a constituição do eu segue passo a passo às denominações com as quais o Outro nomeia sua relação afetiva com o sujeito. E, desse processo, o Eu só surge a posteriori (AULANGNIER, 2001). Assim, pelas suas narrativas, os pacientes psicóticos adentram o espaço político (SURJUS; ONOCKOCAMPOS, 2011; VASCONCELOS et al., 2005), recheando-o com suas vivências, historicamente relegadas à exclusão. A vinda ao mundo dessas histórias constitui-se muitas vezes, por si só, em uma ferramenta de combate ao estigma (BEVERLEY, 2008). Para que exerçam sua função de mediação entre o vivido e o mundo social, parece-nos necessário que as narrativas, ainda, considerem o contexto de produção da experiência e seus determinantes. 
Burke (1992) propôs “densificar” a narrativa, ou seja, construí-la de modo que possa lidar não só com a sequência dos acontecimentos e as intenções conscientes dos atores, como também com as instituiçôes e modos de pensar, ou seja, com as múltiplas vozes envolvidas naquilo que é narrado.

Para Lyotard (2006), toda história que se conta é endereçada a alguém, de modo que um tipo de variável diegética é constituída por aquele que motiva o fato de contar e se dispõe a recolher e registrar essa história de alguma maneira. Com isso desejamos destacar que as narrativas nunca estão "prontas" no interior dos sujeitos, prestes a serem "extraídas": elas são sempre construções que nascem de uma relação. Colocando-nos numa posição de disponibilidade, estando genuinamente presentes e adaptados ao entrevistado, nos sentiremos capazes de desenvolver uma escuta sensível, que nos capacite a construir narrativas agenciadoras daquele fluxo de ideias, descrições de acontecimentos e afetos apresentados durante a entrevista.

A construção de narrativas, tal como a concebemos, é fruto de um processo relacional configurado em um espaço transicional (MIRANDA; ONOCKOCAMPOS, 2010; WINNICOTT, 1971), permeável às (re)vivências e conectado ao seu contexto social de produção. Num modelo político fundamentado na ação e na palavra (mas nunca uma sem a outra).

\section{Efeitos de narratividade}

Temos chamado de efeitos de narratividade aos efeitos de aprofundamento das questōes sobre temas pouco desenvolvidos na primeira sessão. Nos vários grupos temos observamos que questóes tratadas de maneira superficial no primeiro encontro puderam ser problematizadas, e passíveis de uma análise mais detalhada somente após o encontro do grupo com a narrativa que construímos a partir da transcrição de seu primeiro debate.

Sendo a construção narrativa que operamos também uma estratégia de redução do material (passamos de 60-80 páginas para 10 ou 15, o que faz possível a leitura coletiva), era também necessária uma instância de validação desse material. Todas as pessoas disseram se reconhecer nesses textos e nos poucos casos em que houve 
novos participantes na segunda sessão de grupo, essas pessoas ficaram surpresas, dizendo o quanto conseguiam reconhecer o grupo ao qual pertenciam no texto.

E ainda, em poucos casos em que os participantes do grupo quiseram corrigir a narrativa (o que foi sempre aceito pelos pesquisadores), foi para propor a troca de palavras muito carregadas de conotaçóes negativas (como periculosidade, por exemplo) por outras que... eram sinônimos menos carregados de valor simbólico!

\section{Procedimentos de interpretação}

O sentido não é nunca dado, ele tem de ser achado, descoberto, compartilhado em uma cadeia de significação que nos junta a outros humanos.

Para podermos trabalhar com a construção narrativa da forma como o fizemos, nosso pressuposto tem sido o de que, em princípio, os nossos "sujeitos de pesquisa" não mentem. Ou, pelo menos não mentem deliberadamente para nós. Isso não é ingenuidade, é um posicionamento ético-político! Assumindo que existe sempre uma violência da interpretação (AULANGNIER, 2001), sustentamos que não há porque aumentá-la desnecessariamente. Assim, não temos buscado revelar significações por trás do texto, senão procurado colocar um mundo na frente dele, como aconselha Ricoeur (1997). No caso das pesquisas, esse mundo é trazido pelas nossas perguntas iniciais de investigação. Assim, interrogamos o tempo todo o material construído procurando identificar no que ele responde aos nossos questionamentos. Rejeitamos, pois, uma abordagem na qual a tarefa é tomada - quase sempre - como a de extrair certo conteúdo latente de um conteúdo manifesto:"Eles disseram isto elou aquilo, mas - na verdade quiseram dizer aquilo outro", pelo contrario, compartilhamos com nossos sujeitos de pesquisa a vinda ao mundo de um texto. Valorizando mais a possibilidade de dizer, de tomar a palavra, do que uma suspeita sobre o dito.

Podemos resgatar agora, as dimensôes sempre presentes e constitutivas da interpretação, a da análise e a da construção (FREUD, 1975). Esta última, geralmente negligenciada na hora de se apresentar a transparência dos estudos qualitativos (ROUDINESCO; PLON, 1998), parece-nos fundamental como veremos a seguir.

Freud (1975) sustentava que o recurso à construção seria útil toda vez que a cadeia associativa era interrompida. Ao oferecer ao paciente uma versão da história 
(sua compreensão da mesma até o momento em questão), o que apontaria para o terapeuta a correção de sua interpretação (de sua história, de sua narrativa), não seria o fato de o paciente dizer "sim era isso mesmo!" ou ao contrário, "não, não foi nada disso!", mas o fato do paciente ser capaz de retomar sua cadeia associativa. É esse efeito que temos visto acontecer nos grupos, quando o encontro com as narrativas que construímos foram capazes de problematizar e tematizar questóes anteriormente recalcadas ou abordadas de forma muito superficial (sem revelar, por exemplo, conflito ou controvérsias).

Nesse aspecto pode se dizer que a construção é ao mesmo tempo a, na medida em
que permite restabelecer de quintessência da interpretação e uma crítica da interpre-
tação modo coerente a significação global da história de um sujeito em vez de se
ater à apreensão de alguns detalhes sintomáticos (ROUDINESCO; PLON, 1998,
p. 389 - grifo nosso).

Destacamos, pois, a aposta na construção como uma possibilidade de fugir do "furor intepretandis". Como dissemos, essa possibilidade se destaca para nós uma vez que decidimos manter um posicionamento ético-político que não transforme as vozes humanas em objetos, nunca, nunca.

O exercício participativo destacou esse aspecto do trabalho para nós, pois, ao compartilharmos alguns momentos do trabalho de interpretação com os próprios sujeitos da pesquisa, ganhou realce a necessidade de trazer à tona um novo texto e não a de erigirmo-nos nos supostos guardiōes do "verdadeiro sentido" (aquilo que eles - os que não sabem tanto quanto nós - teriam querido dizer, ou esconder, nas suas falas). Para isso, não bastava fragmentar os trechos de falas transcritas com os quais estávamos trabalhando, precisávamos de uma organização do material que trouxesse à tona seu enredo, a saga desses debates avaliativos. Consideramos esse aspecto de fundamental importância na pesquisa em saúde, sobretudo quando vinculada aos serviços, às políticas públicas e à gestão.

Em geral, quem pesquisa nesses campos não busca somente compreender, mas também transformar, propor alternativas, buscar soluções. E essas propostas só podem ser formuladas de forma construtiva, a partir da fase analítica. Ricoeur (1990) propõe essa síntese entre teoria crítica e hermenêutica como procedimento para superar as fronteiras entre o compreender e o explicar! Em certo sentido, disso se ocupou nosso exercício interpretativo: de um intenso, árduo processo de manuseio e organização do material obtido nos grupos focais. 
Uma forma de trabalhar, que nos permitiu a valorização do que se diz, foi codificarmos o material (já organizado como narrativas por nós construídas e após sua validação pelos grupos de interesse) não em relação a temas ou categorias senão por meio dos núcleos argumentais. Um núcleo argumental é um conjunto de frases que não somente se referem a um tema, também tenta atribuir a ele algum tipo de explicação. Explicação no sentido de um porquê, de um para quê e de um como. Os núcleos argumentais não são os temas levantados, porém a "tessitura da intriga" sobre esses temas. Nos grupos focais os temas foram provocados pelos nossos roteiros, e a nossa escuta foi narrativizante (deixou "seguir a história", não interrompendo as falas tanto quanto se faz classicamente nos grupos focais) (MIRANDA et al., 2008).

Oferecemos a seguir exemplos de núcleos argumentais sobre o tema da Crise obtidos de grupos focais realizados com trabalhadores de Caps III:

- A crise não deve ser vista somente como um momento de buscar estabilização, mas como oportunidade de causar alguns desvios, algumas mudanças, de você poder de fato entrar em contato com aquele usuário, testemunhar o movimento de entrada e saída da crise.

- Na nossa prática de trabalho, esta questão da crise tem sido tratada como algo que deve ser sanado o mais rápido possível. Seu tratamento também conta com um suporte medicamentoso muito pesado. Com o passar do tempo, temos pensado que, em situações de crise, não há muito o que inventar. $\mathrm{O}$ paciente precisa ser medicado, encaminhado para o leito e, se estiver agitado ou agressivo fisicamente, contido.

No exemplo acima, mostra-se bem a diversidade de explicações, a diferença radical dos argumentos, se, em ambos, o tema é o do tratamento à crise nos CAPS; no entanto, as explicações e concepçôes clínicas que ambas expressam são evidentemente diversas. Para uns, a crise é momento de oportunidade que não deveria ser desperdiçado; para outros, momento de eclosão de algo ruim que deve ser aplacado o mais rapidamente possível. Não custa imaginar que concepções tão diversas devem levar a ações bem diferentes a hora de intervir com os usuários.

Temos organizado o nosso material de maneira a tornar fácil a sua manipulação como mostramos na tabela a seguir (tabela 1): 


\begin{tabular}{|c|c|c|}
\hline $\begin{array}{c}\text { Nome do grupo } \\
\text { FAMILIARES }\end{array}$ & $\begin{array}{l}\text { Lembrando os } \\
\text { roteiros dos } \\
\text { grupos focais }\end{array}$ & Núcleos argumentais \\
\hline $\begin{array}{l}\text { Tema do grupo: } \\
\text { Sobre as práticas } \\
\text { grupais no Caps }\end{array}$ & $\begin{array}{l}\text { 1. Existem? } \\
\text { 2. Quais funções? } \\
\text { 3. Quais reflexões/ } \\
\text { supervisões? }\end{array}$ & $\begin{array}{l}\text { Em alguns CAPS não está acontecendo a reunião } \\
\text { de família. Isso faz muita falta. Poderíamos } \\
\text { tentar marcar aos sábados, mensalmente. Ou, } \\
\text { quinzenalmente num dia de semana às } 7 \text { da } \\
\text { noite. Cada CAPS tem que se adaptar, mas é } \\
\text { necessário que as reuniōes voltem a ocorrer. } \\
\text { Às vezes desanima-nos, pois poucos familiares } \\
\text { participam das reuniōes. É preciso atraí-los. } \\
\text { Temos muita necessidade de trocar com nossos } \\
\text { pares. Sofremos muito, sentimo-nos ansiosos, } \\
\text { com medo das novas crises e precisamos nos } \\
\text { apoiar uns nos outros. Isso nos dá impulso novo. } \\
\text { A reunião de família é a única prática grupal } \\
\text { mencionada. }\end{array}$ \\
\hline
\end{tabular}

Legenda: Informações em preto: referentes ao primeiro grupo/narrativa.

Informações destacadas em cinza: referentes ao segundo grupo, onde se evidencia o efeito de aprofundamento relatado; como se vê, as pessoas saem de uma posição exclusivamente de queixa e se dispõem a se organizar para produzir alguma mudança na situação que avaliam como indesejável.

Informações em branco com destaque preto: comentários dos pesquisadores responsáveis pela organização do material.

Resumindo nossa modalidade de trabalho: temos empreendido uma forma de processamento do material que procurou se manter, o tempo todo, no manifesto e não à procura do latente. Não estamos com isso negando a existência desse latente. Estamos tentando chamar a atenção para a dimensão ético-política das nossas escolhas técnico-metodológicas e para seus efeitos na própria pesquisa: por um lado, como efeito de qualificação do material qualitativo colhido; por outro, como efeitos de implicação e de envolvimento com o "olhar avaliativo" pelos sujeitos da pesquisa. 
A fixação pela escrita do material audio-gravado, após a construção narrativa, torna o texto relativamente autônomo à intenção do autor, constituindo o que Gadamer (1997) chama de mundo do texto. Para Ricoeur (1990), a escrita liberta o texto da relação dialogal: não há mais vis-à-vis na mesma situação. Por isso, para esse autor, ler e escrever não é um caso particular da relação entre falar e ouvir. Contudo, todo texto mantém uma função referencial: fala sobre alguma coisa que acontece no mundo através de seu enredo (Mythos), constituindo o que Ricoeur (1997) chama de mimesis. A consequência hermenêutica desse procedimento é que o distanciamento não é produto da metodologia (e, neste sentido, algo agregado) senão constitutivo do fenômeno do texto como escrita, sendo também condição de interpretação. Essa questão parece-nos uma contribuição em relação ao que dizíamos na introdução sobre a necessidade de produzir mais estranhamentos do que aculturação no tipo de pesquisas que desenvolvemos.

A apropriação de um texto é o contrário de sua contemporaneidade e contiguidade: é compreensão na distância e pela distância. O distanciamento é a condição da compreensão. Experimentamos assim a construção de um tipo de "corpus" de material qualitativo. O grupo de pesquisa constituiu uma forma de trabalhar na qual a construção do material foi sempre coletiva e na qual se reiteraram os procedimentos varias vezes por pesquisadores diferentes como uma das estratégias de validação também utilizadas.

\section{A produção de consenso além (ou aquém) dos expertos}

Gostaríamos agora de detalhar algumas opções metodológicas em relação à produção de consensos que a participação dos sujeitos de pesquisa nos colocou. Tomando a avaliação como processo participativo e inclusivo, visando à detecção e à consideração das percepções, valores e questôes dos grupos de interesse envolvidos com um dado programa, fomos levados a incluir o maior número de atores no processo: usuários, familiares, gestores com interesse na utilização efetiva dos resultados do processo avaliativo (FURTADO, 2001; FURTADO; ONOCKOCAMPOS, 2008; GUBA; LINCOLN< 1989). A inclusão de diferentes grupos de interesse no processo avaliativo tornou necessária a utilização de metodologias de pesquisa que fossem coerentes com nosso quadro de referências.

Ao assumirmos uma postura ético-política de garantia da participação de diferentes atores nas diversas fases da pesquisa, fomos convocados à criação 
de espaços de reflexão e também de devolutivas dos materiais elaborados nas pesquisas, com o objetivo de envolver os grupos de interesse nas problemáticas em foco e ampliar conjuntamente o conhecimento através do processo avaliativo. Ao revisarmos as clássicas técnicas de consenso, deparamo-nos com as tradicionais técnicas de:

a) Grupos nominais (TNG) ou painel de experts: técnica destinada classicamente a validar evidências qualitativas, não produz um novo debate, facilita o agrupamento de ideias, porém não é recomendada para obter ideias novas. Ocorre de maneira presencial.

b) Técnica Delphi: busca consensos de opiniōes de um grupo de especialistas, sendo os consensos entendidos como a consolidação estatística do julgamento intuitivo do grupo. Trabalha-se com porcentagens e várias rodadas de apresentação do material em análise. Realizada à distância. Opera no anonimato (o que seria uma vantagem em determinados contextos já que não estaria submetendo as opiniōes ao constrangimento do poder-saber).

Esse recurso aos especialistas, muito valioso em outras conjunturas, parecianos inadequado ao nosso desenho até então tão participativo. Perguntávamonos: quem são os experts nas experiências avaliativas de quarta geração? Os próprios grupos de interesse, respondíamos. Então, como produzir o consenso? E ainda preocupava-nos utilizar um critério de validação estatístico quando todo o processo havia acontecido sob a égide da argumentação.

Foi assim que a possibilidade de trabalharmos com uma instância de participação na qual pudéssemos operar a devolutiva dos dados, objetivando incrementar a participação, analisar as potencialidades e limitações da metodologia utilizada, contribuir para criar consensos mínimos para a continuidade e institucionalização do processo avaliativo e produzir a pactuação de um leque de indicadores, parâmetros e dispositivos avaliativos, além de estimular a utilização dos resultados da avaliação pelos grupos de interesse foi se constituindo e demos a essa instância o nome de "oficina".

A palavra oficina vem de ofício (do latim officium) e expressa uma modalidade em que o modo de fazer, além de ser transmitido artesanalmente de uns a outros, tem um sentido de experiência partilhada. Em uma de nossas pesquisas realizamos dez oficinas, com aproximadamente 30 pessoas cada, às quais convidamos, além de nossos sujeitos de pesquisa, novos atores da rede de 
saúde estudada que não haviam participado da fase inicial de grupos focais. Nessas oficinas, portanto - ao contrário dos grupos focais, nos quais se procura a homogeneidade - produzimos encontros de grande heterogeneidade em termos de seus participantes. Conseguimos aumentar a quantidade e diversificar a qualidade dos participantes.

Decidimos organizar as oficinas por temas. Iniciamos cada uma com uma breve apresentação da pesquisa. Logo a seguir, pedimos aos participantes que escolhessem quais dos aspectos apontados pela pesquisa qualitativa, em termos de solução, problema ou controvérsia, seriam priorizados para posterior acompanhamento regular. Esse material foi entregue impresso e organizado em função do tema de cada oficina. Preocupava-nos o manejo da reunião de maneira a não repetir o campo (evitar rediscutir os temas, que pensamos poderia ser uma tendência pela presença de atores que não haviam participado da primeira fase).

Duas semanas depois, houve uma segunda rodada das cinco oficinas; apresentamos o material produzido pela oficina anterior (impresso) e solicitamos aos mesmos participantes que tentassem traduzir as dimensões já destacadas em indicadores ou dispositivos avaliativos. O intervalo de tempo pressupunha que os participantes levariam o material produzido na primeira oficina até seus respectivos serviços e contextos, dando assim um tempo também para a reflexão, visando evitar a tomada de decisão emocional, ao calor dos debates.

Assistimos em todas as oficinas a intensos debates mediados. Os sujeitos do estudo, ao serem colocados em contato não apenas com seus pares, mas também com pessoas de diferentes posiçôes sociais, tiveram que se ouvir em suas diferenças e também que se posicionar, firmando e defendendo avaliaçōes. Ao fazê-lo, precisaram tornar mais claras as suas opiniōes, revê-las e aprofundá-las, o que acarretou interessante processo político de construção de uma autoria coletiva sobre os modos de avaliação da realidade de trabalho. Com isso, destacamos o caráter propositivo das oficinas. Consenso foi obtido a partir da discussão, revisão de posicionamentos, de encontros e discordâncias.

Aqui cabe uma pequena digressão sobre a composição de consenso e a produção de verdades, as relações de poder e o posicionamento dos grupos de interesse no campo. Outros autores já apontaram para momentos de "special kind of epistemological authority as embodying subaltern voice and experience" (BEVERLEY, 2008), questões que comprovamos com o efeito de autoridade que a voz de usuários 
e familiares teve em alguns casos para dirimir as controvérsias que apareciam muitas vezes como irredutíveis entre os diferentes grupos de trabalhadores.

Como exemplo, debatia-se intensamente sobre a conveniência ou não de se assistir à crise nos domicílios. Um grupo de trabalhadores de Caps, argumentando ser uma atividade clínica fundamental para conhecer melhor o usuário e ganhar confiança da família, e outro apontando o perigo dessas intervenções em regiōes da cidade marcadas pela violência e o trafico de drogas. Quando as posições pareciam inconciliáveis, uma familiar interveio comentando que já passara por ambas as experiências em razão da mudança de endereço de sua mãe, idosa, cuidadora de seu irmão psicótico. E afirmou: "eu não tenho dúvidas, quando a equipe se desloca até a casa é muito melhor para minha mãe, para meu irmão e, por conseguinte para mim, que fico muito mais segura para sobrelevarmos a crise sem uma internação". O efeito de suas palavras foi o de estender uma ponte entre ambas as posiçōes, que começaram a se perguntar sobre as condições de trabalho necessárias para garantir esse tipo de assistência a população e já não mais estavam preocupadas em "ganhar" uma discussão.

Uma espécie de mediação pelo testemunho aconteceu. Apontando um ganho de poder assentado no posicionamento social do falante (e sua experiência) e permitido pelo posicionamento ético-político da investigação.

\section{Reflexões finais e (sempre) provisórias}

Pretendemos mostrar como, ao assumir radicalmente as estratégias participativas, fomos levados a rever alguns pressupostos metodológicos da pesquisa qualitativa em Saúde Coletiva. Em nossas modalidades de trabalho, temos sido firmes em rejeitar uma violência na interpretação que, seguindo Piera Aulanguier (2001), chamamos de "desnecessária". Não podemos nos erigir mais em autoridade interpretativa, interpretando aos outros. Buscamos interpretar com os outros. Temos de nos tornar cada vez mais escribas e ajudantes, mas, ajudantes de um movimento de reflexão e crítica. E trazer questões sim. A eles, com eles. Não estamos defendendo uma neo-etnografia, na qual simplesmente nos tornaríamos meros escrivães. Falamos dos efeitos de uma relação e de um trabalho (que até aqui chamamos de efeitos de narratividade). Relação de respeito, de confiança, de carinho que pouco a pouco pudemos construir. Relação viva e marcada pela intensidade amorosa de nossos encontros. E, ao mesmo tempo, rigorosa no campo intelectual. Rejeitamos, 
portanto, também a partir desta experiência de compartilhamento radical com usuários, a dissociação entre afeto e pensamento. Assim, as formas de interpretação, notadamente a construção de narrativas e a utilização dos núcleos argumentais se destacaram para nós. Também as técnicas de construção de consenso precisaram ser revisadas para se adequar aos princípios da inclusão e da diversidade sustentados pela pesquisa avaliativa de quarta geração (GUBA; LINCOLN, 1989).

Ressaltamos que algumas inovaçôes se fizeram possíveis precisamente nesse encontro entre o presente e interesse dos pesquisadores com as tradiçōes da área, como bem nos ensinou Gadamer (1997). Portanto, chamamos a atenção para a importância do estudo das técnicas clássicas e consagradas como ponto de partida indispensável. Pensamos que é somente no limite de sua potencialidade que as inovações se fazem possíveis.

Ainda, destacamos que a possibilidade de inovar só pode ser sustentada por uma forma bastante democrática e muito responsável de funcionamento para "dentro" do grupo de investigação e "entre" os pesquisadores. Grupos assim em nada se parecem com uma cadeia de produção, nem com uma orquestra ou nenhum tipo de organização vertical. Em grupos assim, todos criam e cumprem seus combinados, mas não obedecem. Ninguém é mão-de-obra para o pensamento de outrem. Todos pensam. Todos ganham.

Cremos que essa forma de trabalho na pesquisa qualitativa em Saúde Coletiva teria grande valor para produzirmos um conhecimento que:

- Ajudasse na defesa da vida de pessoas e comunidades.

- Permitisse estabelecer estratégias terapêuticas e preventivas mais potentes (questionando a não adesão a tratamentos, a medicalização da vida social, etc.).

- Contribuísse para jogar luz sobre melhores maneiras de organizar programas e serviços, melhor adaptados as demandas dos grupos de interesse envolvidos.

- A um Estado omisso interessa uma ciência inócua. A nós, o contrário.

\section{Referências}

AULANGNIER, P. La violência de la interpretación. Buenos Aires: Amorrortu, 2001.

BEVERLEY, J. Testimonio, subalternity and narrative authority. In: DENZIN, N.K.; LINCOLN, Y.S. (Eds). Strategies of qualitative Inquiry. 3 ed. Los Angeles: Sage; 2008. p. 257-70. BURKE, P. A escrita da história: novas perspectivas. São Paulo: Unesp, 1992. 
CASTORIARDIS, C. As Encruzilhadas do Labirinto II. São Paulo: Paz e Terra, 1987.

FLICK, U. Introdução à pesquisa qualitativa. São Paulo: Artmed; 2004.

FOSSEY, E. et al. Understanding and evaluating qualitative research. Aust $N Z J$ Psychiatry, v. 36, n. 6, p. 717-32, Dec 2002.

FREUD, S. Construções em análise. Edição standard brasileira das obras psicológicas completas de Sigmund Freud. Rio de Janeiro: Imago, 1975 [1937].

FURTADO, J.P.; ONOCKO-CAMPOS, R. Participation, knowledge production, and evaluative research: participation by different actors in a mental health study. Cad Saude Publica, v. 24, n. 11, p. 2.671-80, Nov 2008.

FURTADO, J.P. Um método construtivista para a avaliação em saúde. Ciência e Saúde Coletiva, v. 6, n. 1, p. 165-82, 2001.

GADAMER, H-G. Verdade e método: traços fundamentais de uma hermenêutica filosófica. Petrópolis: Vozes, 1997.

GUBA, E.G.; LINCOLN, Y.S. Fourth Generation Evaluation. Newbury Park: Sage, 1989.

KRISTEVA, J. O gênio feminino: a vida, a loucura, as palavras. Tomo I - Hanna Arendt. Rio de Janeiro: Rocco, 2002.

LYOTARD, J.F. A condição pós-moderna. 9 ed. Rio de Janeiro: José Olympio, 2006 [1979].

MIRANDA, L. et al. Dos grupos focias aos grupos focais narrativos: uma descoberta no caminho da pesquisa. In: ONOCKO-CAMPOS, R. et al. (Eds). Pesquisa avaliativa em saúde mental. São Paulo: Hucitec, 2008.

MIRANDA, L.; ONOCKO-CAMPOS, R. Narrativa de pacientes psicóticos: notas para um suporte metodológico de pesquisa. Rev Latinoam Psicopat Fund, v. 13, n. 3, p. 441-56, 2010.

MORSE, J.M. Reconceptualizing qualitative evidence. Qual Health Res, v. 16, n. 3, p. $415-$ 22, Mar 2006.

ONOCKO-CAMPOS, R.; FURTADO, J.P. Narratives: use in qualitative health-related research. Rev Saude Publica, v. 42, n, 6, p. 1.090-6, Dec 2008.

RICOUER, P. Interpretação e ideologias. Rio de Janeiro: Francisco Alves, 1990.

Tempo e narrativa. Campinas: Papirus, 1997.

ROUDINESCO, E.; PLON, M. Dicionário de psicanálise. Rio de Janeiro: Jorge Zahar, 1998. SURJUS, L.T.L.S.; ONOCKO-CAMPOS, R. A avaliação dos usuários sobre os centros de atenção psicossocial de Campinas/SP. Rev Latinoam Psicoat Fund, v. 14, n. 1, p. 1.222-333, 2011. VASCONCELOS, E.M. et al. Narrativas de recuperação e convivência com o transtorno mental. Rio de Janeiro: EncantArte, 2005.

WINNICOTT, D.W. O brincar e a realidade. Rio de Janeiro: Imago, 1971. 
Talk to them! The interpretative work and the production of consensus in qualitative health research: innovations from participatory design This paper aims to discuss ways of working with interpretative qualitative research, following participative techniques, including validation and consensus, and narratives construction. These narratives, extracted from argument core, increase the density of the material, keeping the reliability of the history. Then the narrative is presented to the interviewed subjects (hermeneutic moment), the function of the meet is to validate data and produce intervention effects. These narrative effects should be the deepening of issues in need of further discussion, not previously well explored. In the interpretation process, hidden meanings are not investigated; without denying the existence of the latent, the explicit was chosen because the ethical-political positioning of the research (involvement and evaluative position of subjects). Finally, the consensus construction is revised to fit the principles of inclusion and diversity, obtained via Workshop (with discussions, positioning reviews of agreements and disagreements). The value of testimony is pointed out as an empowerment strategy.

Key words: qualitative research, community-based participatory research, methodology, narrative, evaluation research. 